\title{
Biginelli reaction in ionic liquids: synthesis and application of a novel iron catalyst with dual activation
}

\author{
Luciana M. Ramos*1 (PG), Rafael G. da Silva²(PQ), Brenno A. D. Neto'(PQ)
}

${ }^{1}$ Laboratory of Medicinal and Technological Chemistry, Institute of Chemistry, University of Brasília (UnB).

${ }^{2}$ Department of Biochemistry, Albert Einstein College of Medicine of Yeshiva University (USA)

*email: lucianamramos@hotmail.com

Keywords: Biginelli reaction, ionic liquids, iron catalyst

\section{INTRODUCTION}

The Biginelli reaction is an elegant and efficient protocol applied in the synthesis of 3,4dihydropyrimidine-2-(1H)-ones (DHPs). ${ }^{1}$ The interest in this class of compounds is due to their potential as biological active compounds. ${ }^{2}$ In this sense, many methodologies are found in the literature as attempts to a more efficient condition to obtain DHPs derivatives. Based in our interest in catalysis and ionic liquids (ILs), ${ }^{3}$ herein we present a study on the use of a novel ionically-tagged iron catalyst as the promoter of the Biginelli reaction.

\section{RESULTS AND DISCUSSION}

The novel iron catalyst was prepared as shown in Scheme 1.

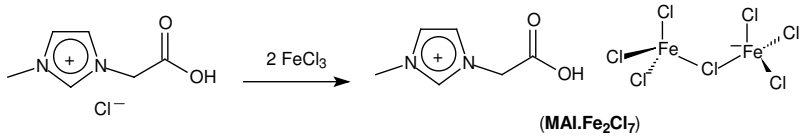

Scheme 1. Synthesis of the novel iron catalyst $\left(\mathrm{MAI} \cdot \mathrm{Fe}_{2} \mathrm{Cl}_{7}\right)$.

The iron catalyst was supported in ILs and applied in the Biginelli reaction (Scheme 2).<smiles>[13CH2]C=O</smiles><smiles></smiles>

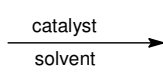<smiles>[Y]C1=C([R9])N([TlH])C([R9])=C(C(=O)O)C1[Y]</smiles>

$\mathrm{R}_{1}=\mathrm{H}$, alkyl or aryl

$\mathrm{R}_{2}=\mathrm{H}$ or alkyl

$\mathrm{X}=\mathrm{O}$ or $\mathrm{S}$

Scheme 2. The Biginelli reaction in ILs promoted by $\mathrm{MAI} \mathrm{Fe}_{2} \mathrm{Cl}_{7}$.

Many conditions were tested to achieve the desired adduct. The best condition was obtained at $80{ }^{\circ} \mathrm{C}$ using $5 \mathrm{~mol} \%$ of the catalyst, $9.00 \mathrm{mmol}$ of benzaldehyde, $3.00 \mathrm{mmol}$ ethyl acetoacetate, 3.00 mmol of urea, $1.0 \mathrm{~mL}$ of $\mathrm{BMI} \mathrm{BF}_{4}$ in $2 \mathrm{~h}$ of reaction. Under the developed condition, the desired DHP derivative was isolated in $99 \%$ yield.

It is worth noting the presence of a Bronsted acid and a Lewis acid in the same structure of the catalyst, allowing a dual activation to promote the reaction. The reaction profile is shown in Figure 1.

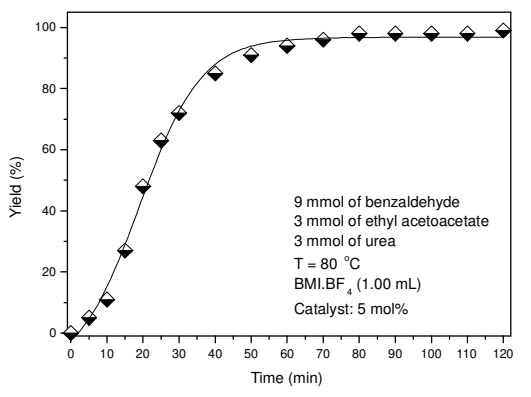

Figure 1. Reaction profile of the Biginelli reaction.

The catalyst was tested with different aldehydes, 1,3-dicarbonyl compounds and urea (or thiourea) resulting in the desired DHPs in excellent yields (8599\%).

Recycling reactions were also tested and at least 8 recharges were performed with no lost of activity (Figure 2).

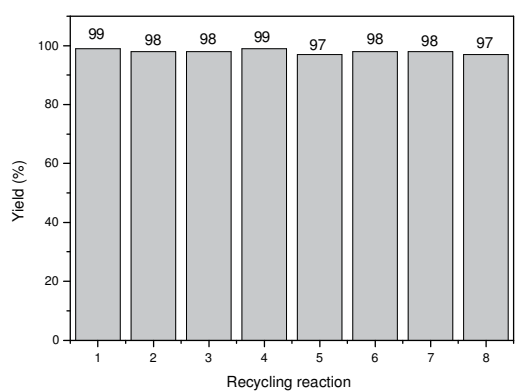

Figure 2. Recycle reactions using MAI. $\mathrm{Fe}_{2} \mathrm{Cl}_{7}$.

\section{CONCLUSION}

A promising iron catalyst has been developed and efficiently tested as the promoter of the Biginelli reaction.

\section{ACKNOWLEDGEMENTS}

CNPq, CAPES, FAPDF for partial financial support.

\section{REFERENCES}

${ }^{1}$ Kappe, C.O J. Org. Chem. 1997, 62, 7201.

${ }^{2}$ Kappe, C.O. Eur. J. Med. Chem. 2000, 35, 1043.

${ }^{3}$ Silva, W. S. D., Lapis, A. A. M., Suarez, P. A. Z., Neto, B. A. D.

J. Mol. Cat. B: Enzymatic 2011, 68, 98. 